\title{
Study on Mechanical Properties and Optimum Fiber Content for Basalt/Polyacrylonitrile Hybrid Fiber Reinforced Concrete
}

\author{
Zhenhai Zeng, Chuanxi Li $\mathbb{D}^{\text {, }}$, Zhuoyi Chen ${ }^{D}$, and Lu Ke \\ School of Civil Engineering, Changsha University of Science and Technology, Changsha 410114, China \\ Correspondence should be addressed to Zhuoyi Chen; chenzhuoyi@csust.edu.cn
}

Received 9 November 2021; Accepted 7 December 2021; Published 18 January 2022

Academic Editor: Erol Yilmaz

Copyright ( $) 2022$ Zhenhai Zeng et al. This is an open access article distributed under the Creative Commons Attribution License, which permits unrestricted use, distribution, and reproduction in any medium, provided the original work is properly cited.

\begin{abstract}
In order to obtain the design method of hybrid fiber reinforced concrete with better mechanical properties, the hybrid effect of fiber and the optimal fiber dosage are studied. In this paper, basalt fiber (B fiber) and polyacrylonitrile fiber (P fiber) were adopted. The mechanical properties such as compressive strength, splitting tensile strength, and bending toughness of concrete specimens with different fiber volumes were tested. The compressive strength, compressive modulus of elasticity, tensile strength, flexural capacity, and bending stress-strain curves of concrete with different fiber volumes were obtained, and the coefficient of hybrid effect and the ratio of toughness were calculated accordingly. The results show that the addition of fiber has little effect on the compressive modulus of elasticity of concrete, and the tensile strength, flexural strength, and toughness ratio are significantly increased, but the compressive strength is slightly decreased. The mechanical properties of hybrid fiber reinforced concrete, such as compressive strength, tensile strength, flexural strength, and toughness ratio, are better than those of single fiber reinforced concrete. The analysis of the fiber hybrid effect coefficient shows that there is a good hybrid effect between the two types of fibers. When the volume contents of B fiber and P fiber are, respectively, $0.15 \%$ and $0.11 \%$, the comprehensive mechanical property of fiber reinforced concrete is the best. Meanwhile, the mechanical properties of the early-age concrete $(3 \mathrm{~d}$ and $7 \mathrm{~d})$ with this admixture are better than those of the plain concrete.
\end{abstract}

\section{Introduction}

After nearly 200 years of development since its inception, concrete has become one of the most important building materials in modern times, but its biggest disadvantage is brittle failure under load and durability problems [1]. Incorporating fibers is an effective way to improve the tensile and flexural properties of the concrete matrix [2-5]. Because the mechanical properties of fiber concrete are largely determined by the fiber properties [6-9] and the properties of each fiber have certain limitations, the reinforcement of a certain fiber alone is limited to the concrete matrix [10-13]. If fibers of different properties are added hybrid, fibers can complement each other through performance advantages to make the matrix have better performance at different levels and loading stages [14-17]. Huang et al. [18] mixed steel fiber (SF) and polypropylene fiber (PF) and conducted mechanical tests such as concrete bending resistance. The results showed that the two kinds of fiber have a good mixing effect. The mechanical properties of compression and flexural strength are better than those of plain concrete and fiber-only concrete, and the flexural strength of concrete increases the most when the volumetric contents of steel fiber and polypropylene fiber are $0.7 \%$ and $0.3 \%$, respectively. Pan [19] studied the influence of basalt fiber (BF) on the mechanical properties of the matrix, and the results showed that the incorporation of basalt fiber can effectively improve the compressive and flexural strength of concrete, with maximum increases of $20 \%$ and $22 \%$, respectively. He et al. [20] studied the mechanical properties of basaltpolypropylene hybrid fiber concrete, and the results showed that the split tensile and flexural strength of hybrid fiber concrete was significantly higher than that of plain concrete and single-mixed fiber concrete. In the existing studies [16-22], most of the fiber hybrid methods use steel fiber, polypropylene fiber, or basalt fiber for hybridization, but 
there are few reports on the hybridization of basalt fiber and polyacrylonitrile fiber. Studies have shown that the incorporation of fibers can also increase the early-age strength of concrete [23-25]. In this research, basalt fiber (B fiber) and polyacrylonitrile fiber ( $\mathrm{P}$ fiber) are mixed to make fiber concrete, and the hybrid fiber concrete compressive, tensile, compressive elastic modulus, and flexural toughness tests are carried out, and the plain concrete and single fiber tests are carried out. The results are compared. In the bending toughness test, the stress-strain curve of the tension zone at the bottom of the test block will be obtained, and the toughness ratio of each test block will be obtained through integration. Subsequently, the best combination of the two fiber reinforced concrete matrixes was obtained by comprehensively combining the results of various mechanical performance tests. This paper will also study the mechanical properties of the concrete and plain concrete at the early ages ( $3 \mathrm{~d}$ and $7 \mathrm{~d}$ ) of the cube compression and splitting tensile and flexural capacity under the optimal fiber blending ratio to verify the hybrid fiber early-age mechanical properties of concrete.

\section{Experimental Program}

2.1. Fiber Properties and Fiber Volume Content. Basalt fiber (B fiber) and polyacrylonitrile fiber ( $\mathrm{P}$ fiber) produced by Wuhan Zhongding Economic Development Co., Ltd. were chosen. The specific material properties of the fiber are shown in Table 1 , where $\rho$ is the fiber density; $\sigma_{b}$ is the tensile strength; $E$ is the elastic modulus; $l$ is the fiber length; $d$ is the fiber diameter; $\delta$ is the fiber elongation at break. The fiber volume content is shown in Table 2 .

\subsection{Concrete Mix Ratio and Specimen Size. P.0 52.5 ordinary} Portland cement produced by Shimen Conch Cement Co., Ltd. is used; coarse aggregate is continuous graded crushed stone (particle size $5 \sim 31.5 \mathrm{~mm}$ ); fine aggregate is yellow sand with low mud content and good gradation; the superplasticizer produced by Hengyang Bangaoweiye Environmental Protection Building Material Technology Co., Ltd. has a water reduction rate of $31.2 \%$; laboratory water. The fiber is measured by volume fraction, the amount of other materials is calculated by mass, and the accuracy of weighing meets the specification requirements. The concrete strength grade is C55. The specific configuration is shown in Table 3.

The test blocks were made in accordance with the "Test Regulations for Hydraulic Concrete" SL 352-2006 and "Standard for Test Methods of Fiber Concrete" CECS: 2009. The size of the cube compressive and split tensile test block is $150 \mathrm{~mm} \times 150 \mathrm{~mm} \times 150 \mathrm{~mm}$, the axial compressive and compressive elastic modulus test block size is $150 \mathrm{~mm} \times 150 \mathrm{~mm} \times 300 \mathrm{~mm}$, the size of the test block for the bending toughness test is $150 \mathrm{~mm} \times 150 \mathrm{~mm} \times 550 \mathrm{~mm}$, and 3 pieces are poured in each group.

2.3. Test Methods. The test methods are those of compressive, tensile, compressive modulus of elasticity, and flexural toughness of the cube in "Testing Regulations for Hydraulic
TABLE 1: Material properties of fibers.

\begin{tabular}{lcc}
\hline Fiber characteristics & BF & PF \\
\hline$\rho\left(\mathrm{kg} \cdot \mathrm{m}^{-3}\right)$ & 2650 & 1180 \\
$\sigma_{\mathrm{b}}(\mathrm{MPa})$ & 4550 & 979 \\
$E(\mathrm{GPa})$ & 99 & 17.6 \\
$l(\mathrm{~mm})$ & 12 & 12 \\
$d(\mu \mathrm{m})$ & 15 & 13 \\
$\delta(\%)$ & 3.1 & 21 \\
\hline
\end{tabular}

TABLE 2: Volume rate of fibers (\%).

\begin{tabular}{lccc}
\hline Concrete type & Symbol & BF & PF \\
\hline Plain concrete & A-1 & - & - \\
\hline & A-2 & 0.1 & - \\
& A-3 & 0.15 & - \\
Single fiber concrete & A-4 & 0.2 & - \\
& P-1 & - & 0.07 \\
& P-2 & - & 0.09 \\
& P-3 & - & 0.11 \\
\hline & H-1 & 0.1 & 0.07 \\
& H-2 & 0.1 & 0.09 \\
& H-3 & 0.1 & 0.11 \\
B-P hybrid fiber dimensional concrete & H-4 & 0.15 & 0.07 \\
& H-5 & 0.15 & 0.09 \\
& H-6 & 0.15 & 0.11 \\
& H-7 & 0.2 & 0.07 \\
& H-8 & 0.2 & 0.09 \\
& H-9 & 0.2 & 0.11 \\
\hline
\end{tabular}

TABle 3: Mix design of concrete $\left(\mathrm{kg} \cdot \mathrm{m}^{-3}\right)$.

\begin{tabular}{lcccc}
\hline Cement & Sand & Gravel & Water & Water reducing agent \\
\hline 494 & 649 & 1204 & 153 & 9.39 \\
\hline
\end{tabular}

Concrete" SL 352-2006 and "Standard for Test Methods of Fiber Concrete" CECS: 2009. $2000 \mathrm{kN}$ YES-2000B servo testing machine is selected for cube compression, compression elastic modulus, and split tensile and axial compression tests, and the loading rate is controlled at $6-7 \mathrm{kN} / \mathrm{s}$.

The bending toughness test adopts three-point loading, and, at the same time, three resistance strain gauges with a length of $50 \mathrm{~mm}$ are sequentially pasted on the bottom surface of the test block in the mid-span transverse direction, as shown in Figure 1. The BX120-50AA series high-precision resistance strain gauge produced by Suzhou Tangdi Technology Co., Ltd. is used, and the load cell is the DYX-306 series cantilever sensor produced by Ningbo Zhongpeng Electric Co., Ltd. The strain value is read every $60 \mathrm{~s}$, and the arithmetic mean value is taken as the tensile strain value in the middle of the test block, and the corresponding bending load is recorded. The test load is controlled by a constant rate, and the load rate is $0.2 \mathrm{~mm} / \mathrm{min}$ until the test is terminated when the block is broken.

\section{Results and Discussion}

3.1. Compressive Performance. Figures 2 and 3 compare the results of the cubic compression and axial compression tests of plain concrete (PC) and fiber concrete test blocks. 


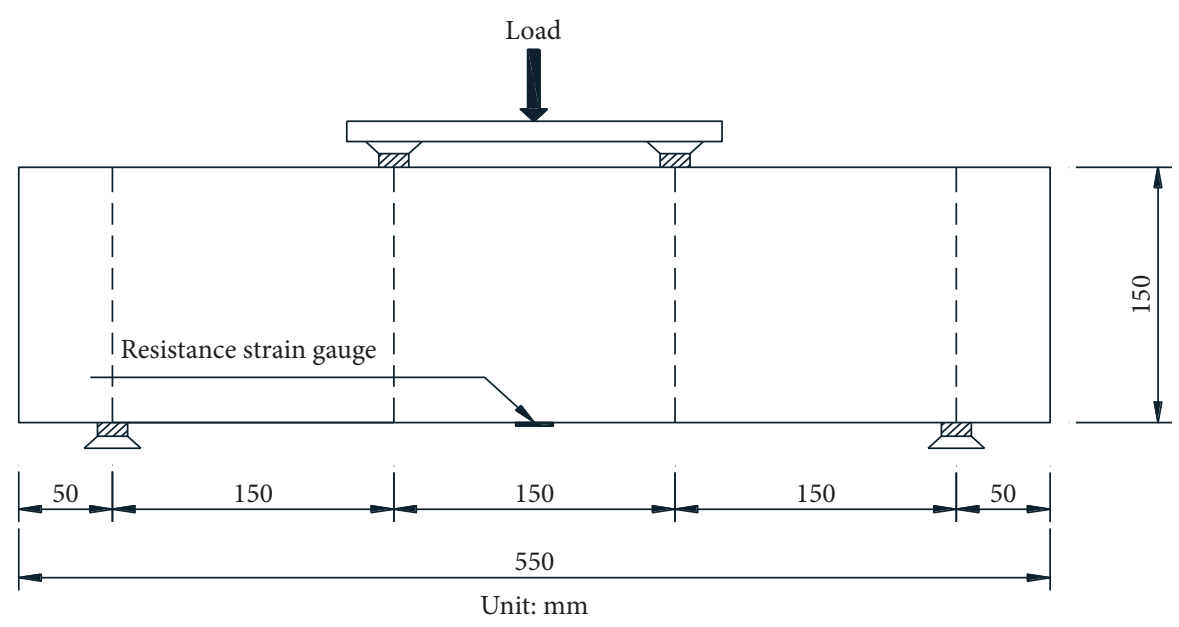

(a)

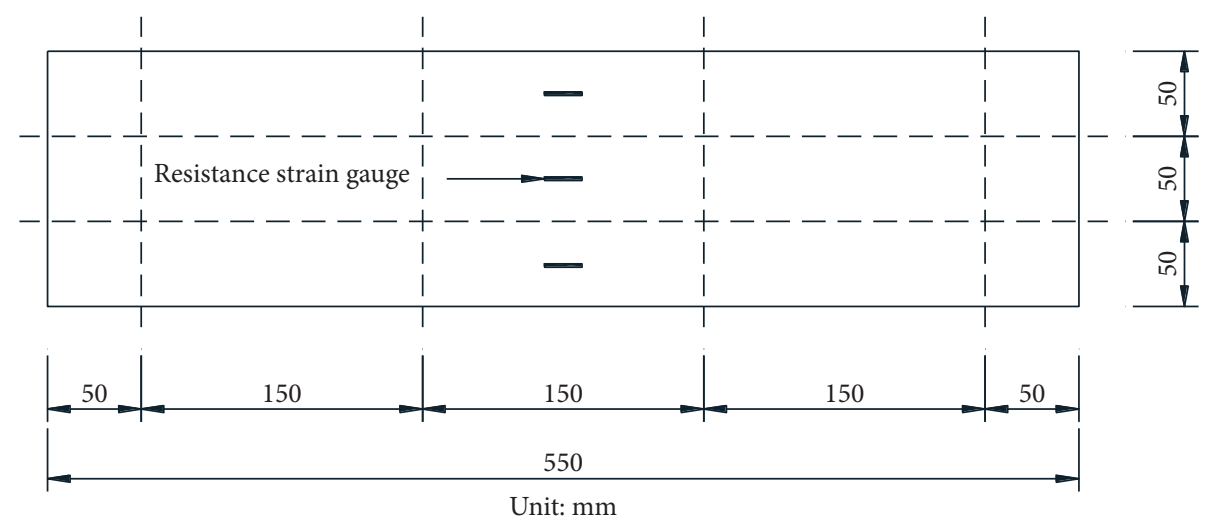

(b)

Figure 1: Flexural toughness test setup. (a) Side view. (b) Bottom of the test piece.

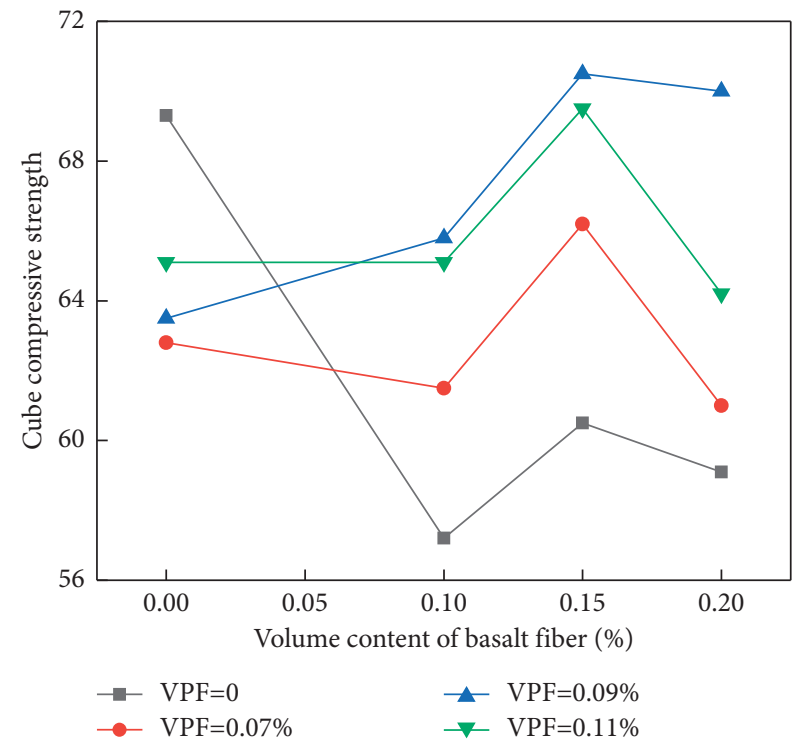

Figure 2: Cube compressive strength effect of concrete with different fiber volume rate.

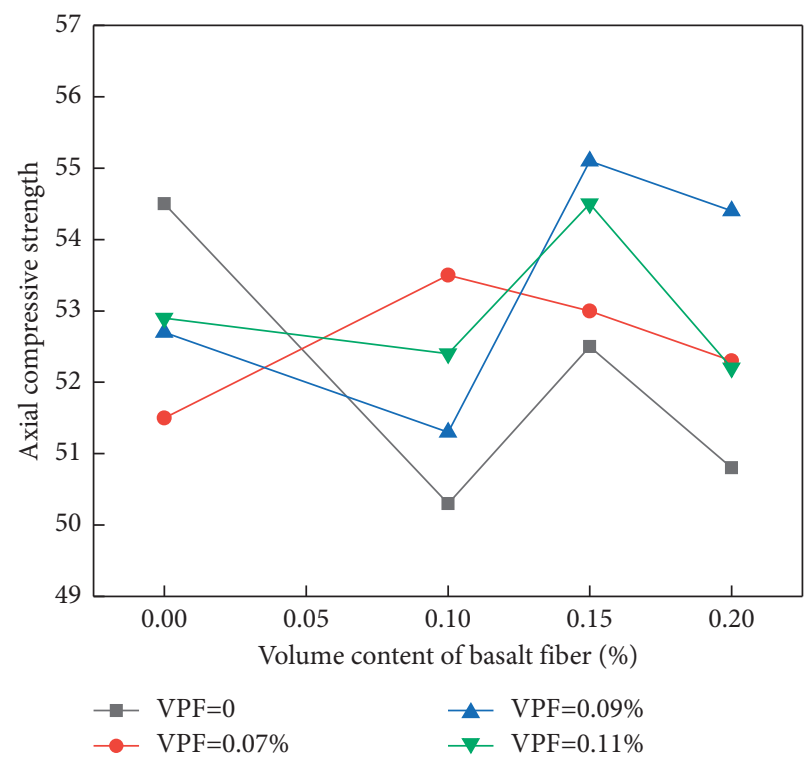

FIGURE 3: Axial compressive strength effect of concrete with different fiber volume rate. 
Regarding the cubic compressive strength, (1) in the general trend, single blending or blending of fibers reduces the cubic compressive strength of the matrix by $0.6 \%$ to $17 \%$. Only when the volumetric content of $\mathrm{BF}$ is $0.15 \%$ and its vicinity is $\pm 0.05 \%$ and the volumetric content of $\mathrm{PF}$ is $0.09 \%$ and its vicinity is $\pm 0.02 \%$ is the compressive strength slightly higher than that of plain concrete (PC) $(1.5 \% \sim 1.6 \%)$. The reason for the analysis is that, in the initial stage of concrete mixing and hardening, the fiber sinks due to its own gravity, resulting in uneven fiber distribution in the matrix, and, at the same time, the phenomenon of fiber sinking and agglomeration, resulting in a cavity in the matrix and a weak section. To a certain extent, it affects the compactness of the matrix, which in turn leads to a decrease in the compressive performance of the concrete matrix. (2) For the compressive performance of basalt fiber concrete (BFRC), with the increase of fiber volume, it shows a trend of first decreasing and then increasing; for the compressive performance of polyacrylonitrile fiber concrete (PFRC) and hybrid fiber concrete (HFRC), with the increase of the fiber volume content, there is a trend of first decreasing and then increasing and decreasing; the reason for the analysis is that when the fiber content is small, the number of effective "carrying networks" formed by the fibers in the matrix is also less. Insufficient quantities cannot overlap each other, which affects the compactness of the concrete matrix and reduces the compressive strength; when the volume of fibers gradually increases to a certain number, and as the "bearing network" increases and overlaps between each other to form a "transmission," "Strength bridge" can inhibit the generation and development of internal cracks in the matrix. When the cracks have appeared, the fibers can pull on the matrix around the cracks, thereby increasing the compressive strength; but when the fiber volume is mixed, when it is too large, the number of fibers in the matrix will be too much, and mutual interference will be formed between the fibers, which will affect the compactness and cohesiveness of the matrix, resulting in a decrease in the compressive strength of the concrete. (3) When the volume content of PF is in the range of $0.07 \% \sim 0.09 \%$ and the volume content of SF is in the range of $0.1 \% \sim 0.2 \%$, the compressive strength of the PFRC test block is better than that of BFRC. (4) The 'negative effect" of the hybrid fiber on the compressive strength of the matrix is lower than that of the single-blended fiber. The reason is that the $\mathrm{BF}$ and $\mathrm{PF}$ have their own advantages. When they are mixed, the two types of fiber can "achieve strengths and avoid weaknesses" in the matrix and played a very good synergy. In summary, the $\mathrm{H}-5, \mathrm{H}-6$, and $\mathrm{H}-8$ test blocks have relatively better compressive performance, (5) From Figure 2, it can be seen that the changing trend of the axial compressive strength of each fiber concrete and the cube resistance the changing trend of compression results are similar. (6) Integrating the results of the cube and axial compression tests, the optimal blending amounts of fiber in this test are $V_{B}=0.15 \%$ and $V_{p}=0.09 \%$ ( $\mathrm{H}-5$ test block).

The following can be seen from Figure 4. (1) The PC concrete test block almost immediately loses its ability to resist deformation after reaching the peak of the cubic compressive stress, showing obvious brittle failure; meanwhile, for the fiber-doped concrete test block under the cubic compressive load, the stress-strain curve can be roughly divided into two stages, namely, the elastic stage and the plastic failure stage. After the load reaches the peak value, it can maintain a certain resistance to deformation. (2) It can be seen from Figure 4(a) that the stress-strain curve of the BFRC test block with different fiber volume content has a higher slope than the PC test block during the load rise stage, indicating that as the load increases, the BF blending increases the ability of concrete to resist deformation which is increased to a certain extent, and the ability to resist deformation is the largest when the volume of BFRC single fiber is $0.15 \%$. (3) Figure 4(b) shows the stress-strain curve of the test block under different PFRC fiber volume content. When the PF volume content is $0.07 \% \sim 0.09 \%$, the strain rate (slope) of the PFRC test block is greater than that of PC, which indicates that when the load is rising, PF fiber also improves the ability of the matrix to resist deformation; when the PF content reaches $0.11 \%$, the slope of the stressstrain curve of the PFRC test block is smaller than that of the PC, and the "negative effect" described above appears. (4) It can be seen from Figures 4(c) and 4(d) that the volumetric content of BFRP is $0.10 \% \sim 0.15 \%$, and when the content of PFRC is arbitrary, the slope of the stress-strain curve of the hybrid fiber concrete test block is uniform. Greater than PC, at this time, the two fiber hybrid effects show a synergistic effect and play a role in delaying deformation. When the BFRC volume content reaches $0.20 \%$, only the slope of the $\mathrm{H}-8$ test block is greater than that of the PC, indicating that, due to the excessive number of fibers, the fibers interfere with each other, which has a "negative effect" on the matrix. (5) Figure 2 and Table 4 show the results: when the fiber volume content of the BFRC test block is $0-0.2 \%$, the compressive peak value shows a trend of first increasing and then decreasing; when the fiber volume content of the PFRC test block is 0 , when $\sim 0.11$ changes, its compressive peak value also shows a trend of first increasing and then decreasing; for HFRC test block, when the volume of BF remains unchanged, its compressive peak value is large as the volume of PF increases, and it shows a trend of first increasing and then decreasing. When the volumetric content of $\mathrm{PF}$ remains unchanged, its compressive peak value generally shows a trend of first increasing and then decreasing with the increase of the volumetric content of BF.

3.2. Test Block Failure Form. In the cubic compression test, the PC, BFRC and HFRC blocks decrease immediately when the load reaches the maximum value. The surface of the PC test block fell off and was seriously damaged and finally showed an "I" shape or a cone shape; see Figure 5(a). The surface shedding phenomenon of BFRC test block is obviously better than that of PC, as shown in Figure 5(b); in the compression test of HFRC test block, when the load reaches the maximum value, it will not decrease immediately but will have a certain hysteresis, and most of the surface of the test block will not fall off by itself when it is broken, and it can maintain the original shape as a whole, as shown in Figure 5(c). From the damage morphology, it can be verified 


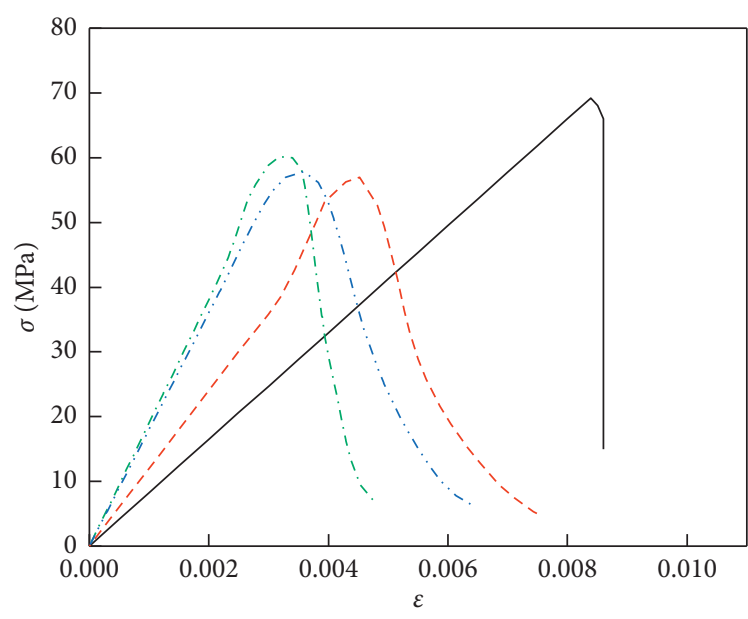

$\begin{array}{rr}- & \text { A-1 } \\ --- & \text { A-2 }\end{array}$

-. - A-3

$\cdot \cdots \cdot \mathrm{A}-4$

(a)

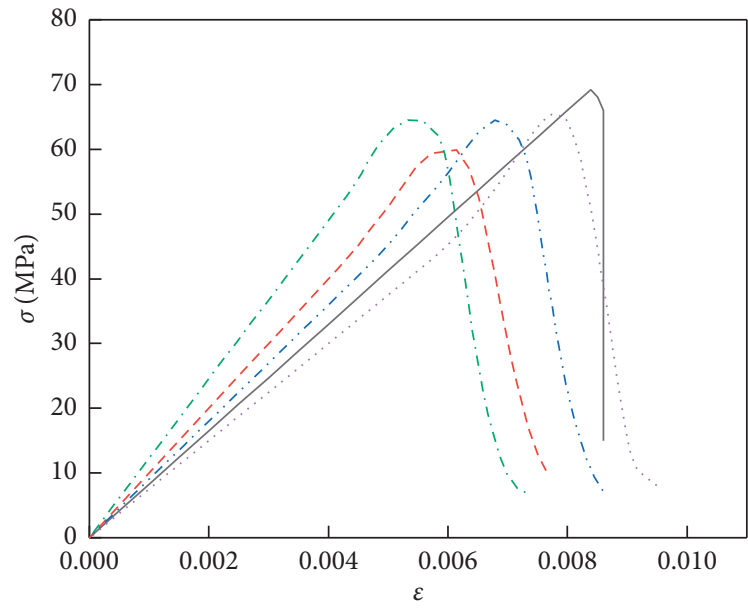

$\begin{array}{ll}- & \text { A-1 } \\ --- & \mathrm{H}-1 \\ -.- & \mathrm{H}-2\end{array}$
- - ... H-3

$\mathrm{H}-4$

(c)

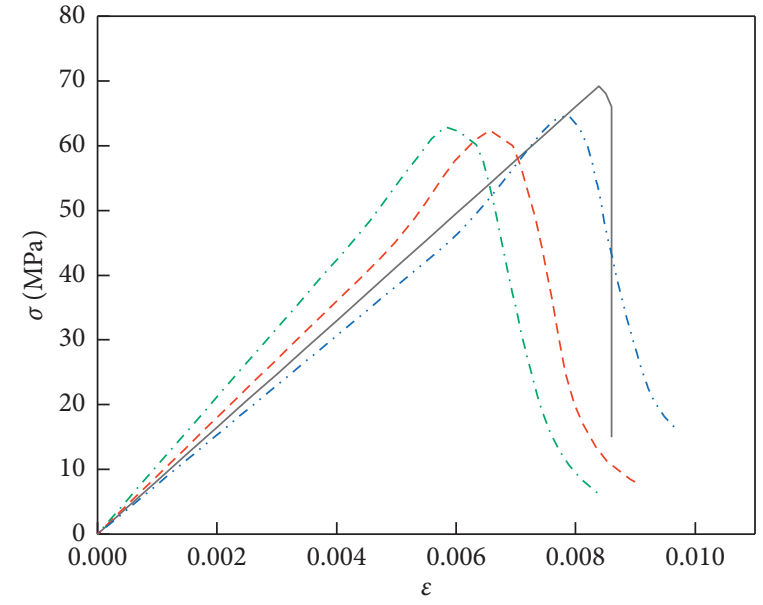

$-\mathrm{A}-1$

-.. P-2

. - . P -3

(b)

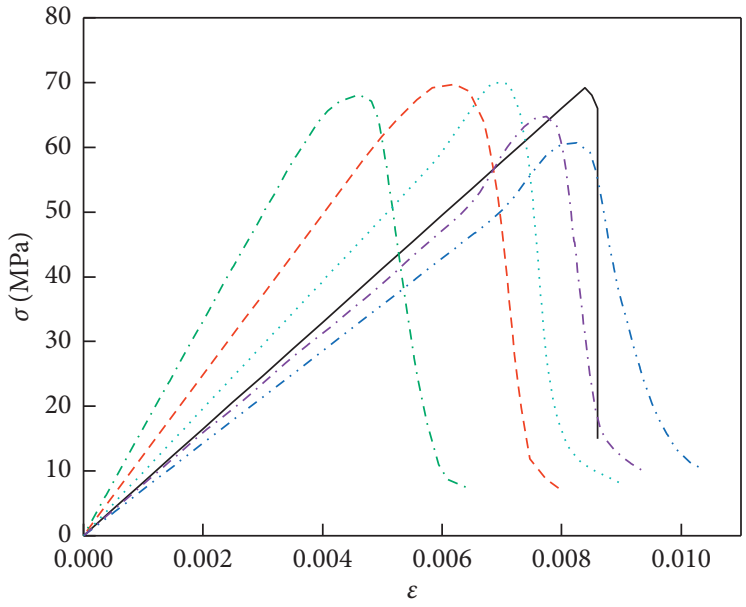

$\begin{array}{ll}- & \text { A-1 } \\ --- & \text { H-5 } \\ -. & \text { H-6 }\end{array}$

- - ... H-7

H-9

(d)

FIgure 4: Comparison of cubic compressive stress-strain curves with different fiber content (before the peak). (a) PC and BFRC, (b) PC and PFRC, (c) PC and H-1 H-4, (d) PC and H-5 H-9.

that the fibers mentioned above can have a pulling effect on the matrix around the crack and can also have a certain inhibitory effect on the development of the crack. For the concrete test block, the failure mode in the axial compression test is basically the same as the cube compression test.

3.3. Tensile Performance. Figure 6 shows the comparison of split tensile test results between the PC test block and fiber concrete test block. The results show the following: (1) The incorporation of fibers can significantly improve the tensile properties of the concrete matrix. In the case of fiber mixing, except for the $\mathrm{H}-1$ and $\mathrm{H}-4$ test blocks, which are slightly lower than PC, all the test blocks have a greater improvement. The maximum increase can reach
18.6\%. (2) For the single-mixed fiber concrete, except for the BFRC test block with a volume of $0.1 \% \mathrm{BF}$, which is $5.5 \%$ lower than that of PC, the tensile properties of all the other single-mixed fiber test blocks are better than those of PC. The range is $1.5 \% \sim 17.5 \%$. At the same time, for BFRC test block and PFRC test block, the tensile strength increases with the increase of fiber volume. (3) When the volume of $\mathrm{BF}$ is in the range of $0 \%$ to $0.15 \%$, the volume of $\mathrm{PF}$ is $0.09 \%$ and 0.11 . \% tensile strength is obviously better than $0 \%$ and $0.07 \%$ series; this is because when the total fiber content is not large, the small and low elastic modulus of PF which is more uniformly dispersed into the matrix during the mixing process to improve the fiber distribution inside the matrix is greatly reduced so that the probability of larger fiber spacing and early cracks in the matrix is greatly reduced. However, when the volume 
TABLE 4: Calculation results of fiber mixed effect coefficient.

\begin{tabular}{|c|c|c|c|c|c|c|c|c|c|}
\hline \multirow{2}{*}{ Symbol } & \multicolumn{3}{|c|}{ Cube compressive } & \multicolumn{3}{|c|}{ Splitting tensile } & \multicolumn{3}{|c|}{ Flexural capacity } \\
\hline & $f_{\mathrm{cc}}(\mathrm{MPa})$ & $f_{\mathrm{ct}}(\mathrm{MPa})$ & $\alpha$ & $f_{\mathrm{cc}}(\mathrm{MPa})$ & $f_{\mathrm{ct}}(\mathrm{MPa})$ & $\alpha$ & $f_{\mathrm{cc}}(\mathrm{MPa})$ & $f_{\text {ct }}(\mathrm{MPa})$ & $\alpha$ \\
\hline \multirow{2}{*}{$\mathrm{H}-1$} & \multirow{2}{*}{61.01} & 57.39 & \multirow{2}{*}{0.37} & \multirow{2}{*}{4.6} & 4.42 & \multirow{2}{*}{0.29} & \multirow{2}{*}{5.62} & 6.06 & \multirow{2}{*}{0.35} \\
\hline & & 62.36 & & & 4.73 & & & 5.37 & \\
\hline \multirow{2}{*}{$\mathrm{H}-2$} & \multirow{2}{*}{65.29} & 57.39 & \multirow{2}{*}{0.48} & \multirow{2}{*}{5.14} & 4.42 & \multirow{2}{*}{0.49} & \multirow{2}{*}{6.7} & 6.06 & \multirow{2}{*}{0.55} \\
\hline & & 63.40 & & & 4.93 & & & 5.73 & \\
\hline \multirow{2}{*}{$\mathrm{H}-3$} & \multirow{2}{*}{64.96} & 57.39 & \multirow{2}{*}{0.45} & \multirow{2}{*}{5.6} & 4.42 & \multirow{2}{*}{0.58} & \multirow{2}{*}{6.58} & 6.06 & \multirow{2}{*}{0.52} \\
\hline & & 65.22 & & & 5.51 & & & 6.01 & \\
\hline \multirow{2}{*}{$\mathrm{H}-4$} & \multirow{2}{*}{66.11} & 60.21 & \multirow{2}{*}{0.52} & \multirow{2}{*}{4.6} & 4.7 & \multirow{2}{*}{0.28} & \multirow{2}{*}{5.95} & 6.6 & \multirow{2}{*}{0.38} \\
\hline & & 62.36 & & & 4.73 & & & 5.37 & \\
\hline \multirow{2}{*}{$\mathrm{H}-5$} & \multirow{2}{*}{70.24} & 60.21 & 0.57 & 503 & 4.7 & 0.51 & 6.23 & 6.6 & 0.44 \\
\hline & & 63.4 & & & 4.93 & 0.51 & 0.23 & 5.73 & 0.44 \\
\hline H-6 & 68.7 & 60.21 & 0.54 & 579 & 4.7 & 063 & 685 & 6.6 & 0.58 \\
\hline & & 65.22 & 0.54 & 5.79 & 5.51 & 0.05 & 0.03 & 6.01 & 0.30 \\
\hline H-7 & 60.97 & 58.54 & 0.36 & 4.7 & 5.15 & 0.32 & 5.73 & 6.55 & 0.33 \\
\hline & & 62.36 & 0.50 & 4.1 & 4.73 & & & 5.37 & \\
\hline H-8 & 7013 & 58.54 & 0.57 & 501 & 5.15 & 048 & 583 & 6.55 & 0.35 \\
\hline & & 63.4 & 0.07 & 3.01 & 4.93 & & 3.03 & 5.73 & 0.35 \\
\hline $\mathrm{H}-9$ & 64.97 & 58.54 & 0.45 & 4.37 & 5.15 & 0.23 & 5.98 & 6.55 & 0.38 \\
\hline & ו & 65.22 & 0.45 & 4.37 & 5.51 & 0.23 & 5.98 & 6.01 & \\
\hline
\end{tabular}
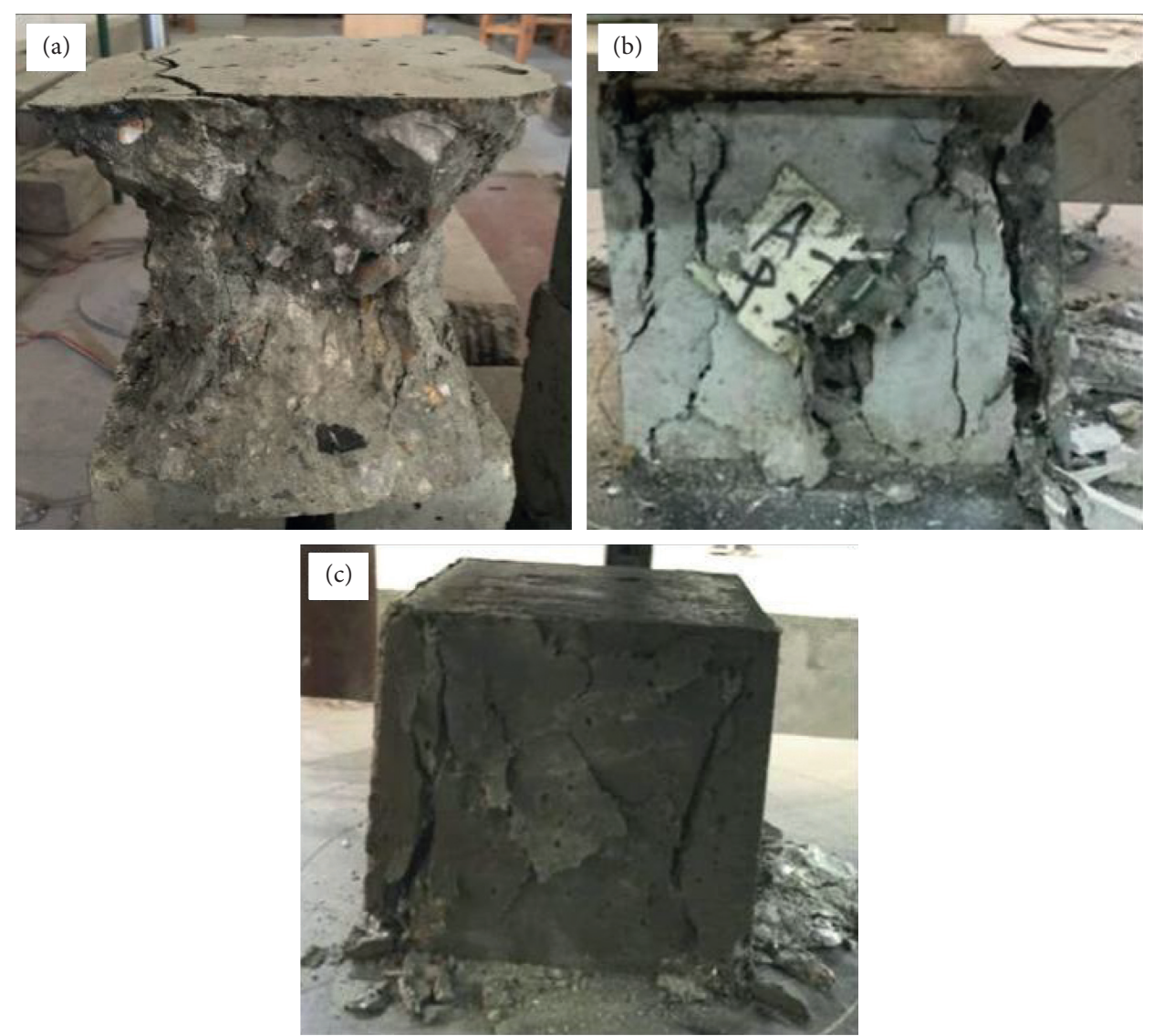

Figure 5: Block destroyed mode of cubic compression. (a) PC, (b) BFRC, and (c) HFRC.

of $\mathrm{BF}$ content reaches $0.2 \%$, the tensile strength of the $0.11 \%$ series of PF content drops sharply, indicating that the "negative effect" mentioned above will be highlighted when the total amount of fiber is too large. (4) For PF, the tensile strength of the test blocks with the volume contents of $0 \%$ and $0.07 \%$ showed a trend of first decreasing and then increasing with the increase of the BF content, while the test blocks with the volume contents of $0.09 \%$ and $0.11 \%$ reduced first and then increased. This is because the synergistic effect of various fibers at different 


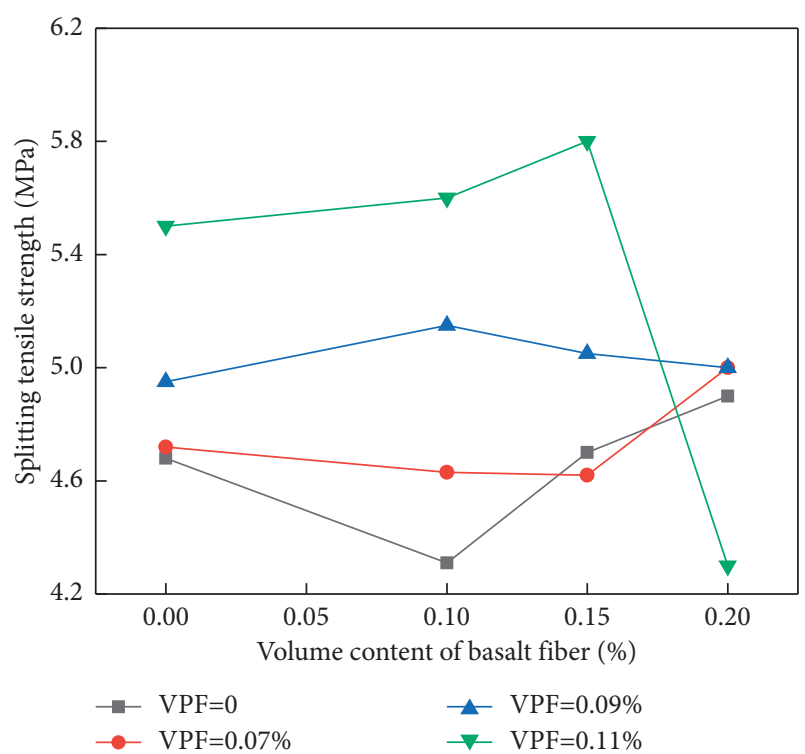

FIGURE 6: Splitting tensile strength effect of concrete with different fiber volume rate.

stages and different structural levels of the test block will change with the change of fiber volume. That is, when the fiber content is small, the number of fibers in the matrix forming an effective "bearing network" is small and they cannot overlap each other, which affects the compactness of the concrete matrix and causes the splitting tensile strength to decrease; when the fiber volume gradually increases to a certain amount, as the "bearing network" increases and the fibers overlap each other to form a "force transmission bridge," it can inhibit the generation and development of internal cracks in the matrix and can also pull the matrix around the cracks. To increase the splitting tensile strength, at the same time, too much fiber will cause the performance of the matrix to decrease. (5) For splitting, the results of the crack tensile test showed that the tensile strength of H-6 specimens was the highest when the BF content was $0.15 \%$ and the PF content was $0.11 \%$, which was $18.6 \%$ higher than that of PC.

3.4. Compressive Modulus of Elasticity. The comparison between the compressive elastic modulus test results of each fiber concrete test block and PC is shown in Figure 7. It can be seen that the compressive elastic modulus of each fiber concrete test block has a small change range compared with PC, and the maximum fluctuation range is only $4.1 \%$. Because its test value largely depends on the axial compressive strength value, the overall change trend is also similar to the axial compressive strength. According to the principle of superposition in material mechanics, the elastic modulus of the composite can be considered as the sum of the product of the matrix and fiber's respective elastic modulus and the volume rate (1). Therefore, when the absolute value of the fiber content is low and considering the "negative effect" of fiber concrete, the change of its elastic modulus is very limited.

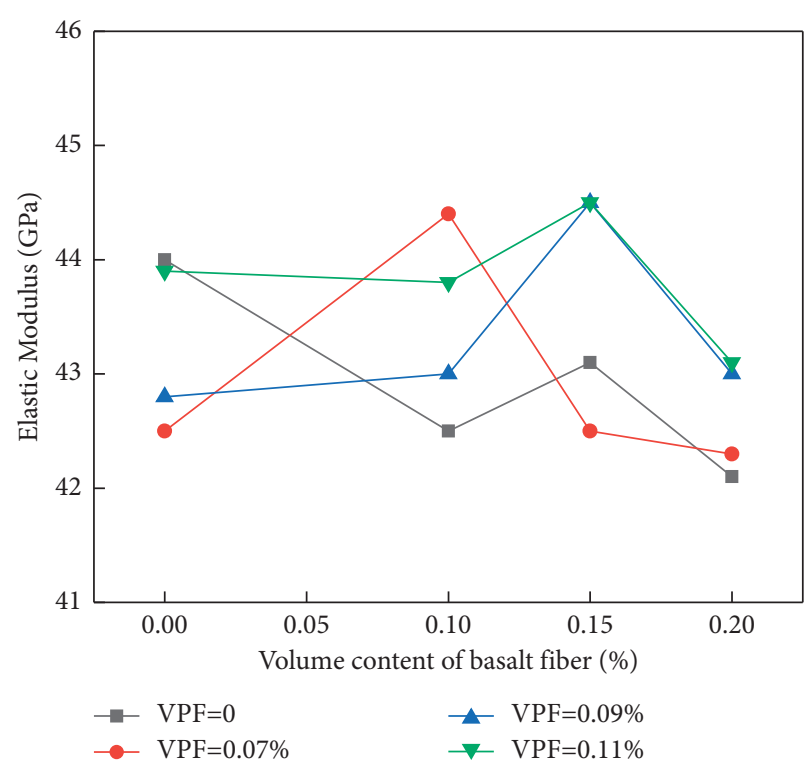

FIgURE 7: Compression modulus effect of concrete with different fiber volume rate.

$$
E=E_{\mathrm{ft}}+E_{B} V_{B}+E_{P} V_{P}
$$

In the above formula, $E$ is the elastic modulus of fiber concrete; $E_{\mathrm{ft}}, E_{B}$, and $E_{P}$ are the elastic moduli of plain concrete, $\mathrm{BF}$, and $\mathrm{PF}$, respectively; $V_{B}$ and $V_{P}$ are the volume contents of $\mathrm{BF}$ and $\mathrm{PF}$, respectively.

3.5. Calculation of Flexural Toughness Ratio. The bending stress can be calculated according to formula (2). The toughening effect of fiber on concrete or the deformability of fiber concrete is usually expressed by the toughness $R$. The toughness of each test block in this paper is calculated by the bending load stress-strain curve. The stress-strain curve of each concrete test block is shown in Figure 6.

$$
\sigma_{f}=\frac{P l}{b h^{2}},
$$

where $P$ is the bending load, $\mathrm{N} ; l$ is the span, $l=3 \mathrm{~h}, \mathrm{~mm} ; b$ and $h$ are the width and height, respectively, of the test block section, $\mathrm{mm}$.

In the test, it was found that, with the increase of the load, the cracks on the bottom surface of the trabecular continued to increase. When the cracks developed to a certain width, the midspan tensile strain changed significantly and even became negative. At this time, the resistance strain gauges have been broken. Furthermore, after the PC reaches the peak of the bending load, it quickly breaks and loses its continued load-bearing capacity. Therefore, this paper only plots the stress-strain curve before the test beam reaches the peak of the bending load.

The area enclosed by the stress-strain curve of each test block is calculated by integrating the stress-strain curve of each test block, and this area is the corresponding bending toughness of the test block [26]. In this paper, the area enclosed by the PC block curve is taken as the unit area, and 
TABLE 5: Calculation results of the ratio of toughness.

\begin{tabular}{lccc}
\hline Symbol & $\sigma_{f}(\mathrm{MPa})$ & $D(\mathrm{~mm})$ & \\
\hline A-1 & 5.08 & 5.3 & $R_{x}$ \\
A-2 & 5.17 & 8.9 & 1.8 \\
A-3 & 5.73 & 9.5 & 2.5 \\
A-4 & 6.01 & 9.2 & 2.4 \\
P-1 & 6.16 & 10.5 & 2.0 \\
P-2 & 6.6 & 13.6 & 2.7 \\
P-3 & 6.55 & 11.9 & 2.7 \\
H-1 & 5.82 & 12.2 & 3.5 \\
H-2 & 6.7 & 14.8 & \\
H-3 & 6.58 & 13.1 & \\
H-4 & 5.95 & 9.9 & \\
H-5 & 6.23 & 10.8 & 3.7 \\
H-6 & 6.85 & 15.3 & 3.1 \\
H-7 & 5.73 & 12.9 & 3.6 \\
H-8 & 5.83 & 10.9 & 4.4 \\
H-9 & 5.98 & 8.3 & 2.9 \\
\hline
\end{tabular}
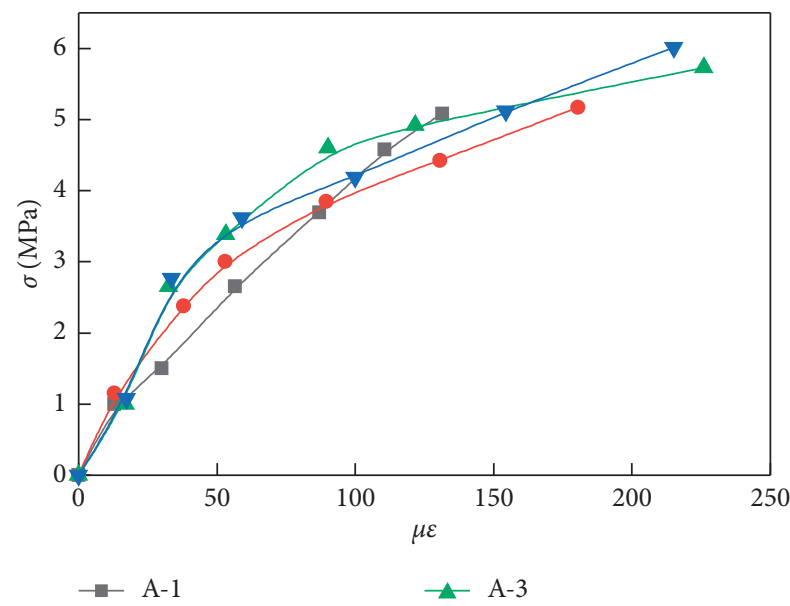

$\rightarrow \mathrm{A}-2$

$\rightarrow \mathrm{A}-3$

$\rightarrow \mathrm{A}-4$

(a)

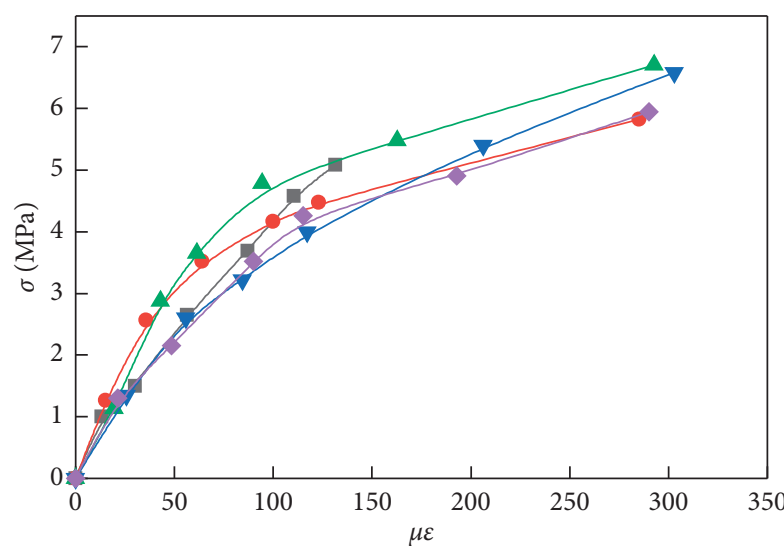

$\rightarrow-\mathrm{A}-1$

$\rightarrow \mathrm{H}-1$

$\rightarrow \mathrm{H}-3$

$\multimap \mathrm{H}-4$

(c)

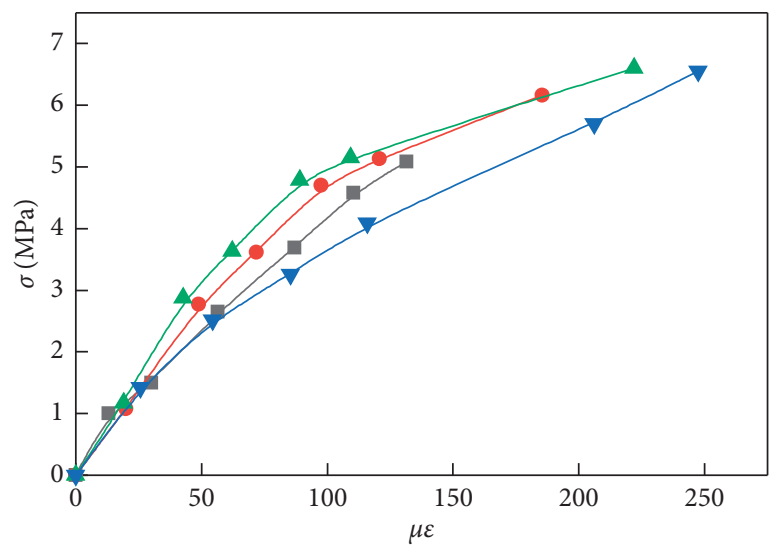

$\rightarrow$ A-1

$\rightarrow$ P-2

$\rightarrow$ P-1

$\rightarrow$ P-3

(b)

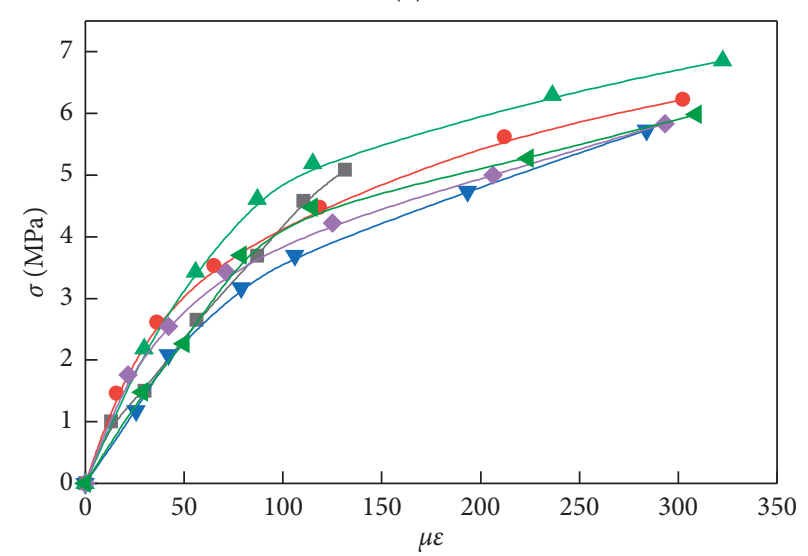

$\rightarrow$ A-1
- H-5
$\rightarrow$ H-6

$\rightarrow$ H-7

$\neg$ H-8

$\longrightarrow$ H-9

(d)

FiguRE 8: Comparison of stress-strain curves of concrete with different volume rates of fibers (before the peak value of flexural capacity). (a) PC and BFRC, (b) PC and PFRC, (c) PC and H-1 H-4, (d) PC and H-5 H-9. 
TABLE 6: Mechanical properties of H-6 specimen and unreinforced concrete at an early age.

\begin{tabular}{lcccccccccc}
\hline \multirow{2}{*}{ Symbol } & \multicolumn{3}{c}{$f_{\text {cc }}(\mathrm{MPa})$} & \multicolumn{3}{c}{$f_{\mathrm{ts}}(\mathrm{MPa})$} & \multicolumn{4}{c}{$\sigma_{f}(\mathrm{MPa})$} \\
& $3 \mathrm{~d}$ & $7 \mathrm{~d}$ & $28 \mathrm{~d}$ & $3 \mathrm{~d}$ & $7 \mathrm{~d}$ & $28 \mathrm{~d}$ & $3 \mathrm{~d}$ & $7 \mathrm{~d}$ & $28 \mathrm{~d}$ \\
\hline A-1 & 56.39 & 60.96 & 69.11 & 3.94 & 4.41 & 4.88 & 4.47 & 4.89 & 5.08 \\
H-6 & 60.52 & 63.00 & 68.70 & 4.75 & 5.24 & 5.79 & 5.31 & 5.97 & 6.85 \\
\hline
\end{tabular}

the ratio of the toughness of each fiber concrete block to PC is the toughness ratio $R_{x}$. Table 5 shows the peak flexural stress $\sigma_{f}$ (accurate to $0.01 \mathrm{MPa}$ ), the flexural elastic modulus $E_{f}$ (accurate to $1 \mathrm{MPa}$ ), the maximum crack width $D$ in the middle of the span, and the toughness ratio $R_{x}$ (accurate to $0.01 \mathrm{MPa}$ ).

The following can be seen from Figure 8 and Table 5 . (1) The PC test block quickly broke after reaching the peak of the bending stress and lost its deformability, showing obvious brittle failure, while the fiber concrete test block remained deformed after the peak. The toughness ratio increases with the increase of $\mathrm{BF}$ and shows a decreasing trend. (2) Figure 8(a) shows that the stress-strain curve of the BFRC test block with different fiber volume content has a larger slope before it intersects with the PC, indicating that $\mathrm{BF}$ has a role in delaying the deformation as the load increases in the first half of the deformation. The toughness of the matrix is increased to a certain extent. (3) When the volume of PF is between $0.07 \%$ and $0.09 \%$, the strain rate or slope of the PFRC test block is less than that of PC, and PF also plays a role in delaying deformation. When the PF volume content increases to $0.11 \%$, the "negative effect" mentioned above occurs, and the strain rate of the PFRC test block is larger. (4) The calculation result of the bending resistance peak value shows that when the fiber volume content in the BFRC test block is in the range of $0 \sim 0.2 \%$, the peak value of bending resistance increases with the increase of fiber; when the volume of fiber in the PFRC test block is in the range of $0 \sim 0.11 \%$, the peak value of bending resistance first increases and then decreases; for the HFRC test block, when the volumetric content of BF remains unchanged, its peak bending resistance shows an increasing trend with the volumetric content of PF. When the volumetric content of PF remains unchanged, its peak bending resistance increases with the increase of BF. The trend is first roughly increasing and then decreasing. (5) The calculation results of the toughness ratio show that, for the single fiber concrete test block, within the fiber volume content range in this paper, the toughness ratio basically increases with the increase of the fiber volume content. For the HFRC test block, when the BF content remains the same, the toughness ratio basically increases with the increase of PF; when the PF content remains the same, plastic failure is obviously shown. It shows that, within the range of fiber content specified in this study, PF has a better toughening effect on the matrix than BF. (6) When the fiber content is large, it will also have a "negative effect" on the toughness ratio of the HFRC test block, such as H-7 and H-9 test blocks, which have the best toughness ratio compared to H-6. The test block decreased by $34 \%$ and then $18 \%$, but the toughness ratio of the HFRC test block was better than that of the singledoped fiber test block.

3.6. Early-Age Concrete Mechanical Properties. Through the test results and calculations, it can be obtained that the relative best combination of hybrid fiber blending amounts in this test is $V_{B}=0.15 \%$ and $V_{P}=0.11 \%$ (H-6 test block). Table 6 shows the test results of the cubic compressive strength $f_{\mathrm{cc}}$, splitting tensile strength $f_{\mathrm{ts}}$, and flexural bearing capacity $\sigma_{f}$ of the early age ( $3 \mathrm{~d}$ and $7 \mathrm{~d}$ ) of the PC test block.

The results show that fiber can also significantly enhance the mechanical properties of early-age concrete. Among them, the compressive strength, splitting tensile strength, and flexural bearing capacity of the H-6 test block at $3 \mathrm{~d}$ age reached $88.1 \%$, $82.0 \%$, and $77.5 \%$ of its $28 \mathrm{~d}$ strength, respectively. The PC increased by $7.3 \%, 20.6 \%$, and $18.8 \%$; the 3 intensity values of the $\mathrm{H}-6$ test block at $7 \mathrm{~d}$ age reached $91.7 \%, 90.5 \%$, and $87.2 \%$ of its own $28 \mathrm{~d}$ intensity, which was higher than that of PC at $7 \mathrm{~d}$ age, increasing by $3.3 \%, 18.8 \%$, and $22.1 \%$.

\section{Calculation of Fiber Confounding Effect Coefficient}

The hybrid effect between basalt fiber and polyacrylonitrile fiber is evaluated from the theoretical point of view of the fiber hybrid effect coefficient. The calculation of the fiber confounding effect coefficient also considers the role of every single-blended fiber, and the fiber confounding effect coefficient is calculated based on literature [23-25]; see the following equation:

$$
\left\{\begin{array}{l}
\alpha=\frac{S-\beta}{\beta} \\
\beta=\sum S_{\mathrm{i}} \varphi_{\mathrm{i}}
\end{array}\right.
$$

where $\alpha$ is the fiber mixing effect coefficient; $S$ is the mechanical performance test result of the HFRC test block; $S_{\mathrm{i}}$ is the mechanical performance result of the single $\mathrm{i}$-doped fiber test block; $\varphi_{\mathrm{i}}$ is the volume fraction of the single $\mathrm{i}$-doped fiber.

Formula (3) is the fiber mixing coefficient calculated for single fiber mixed, so the test results of PC block are ignored here. When $\alpha>0.5$, it will produce a positive effect relative to single fiber concrete, and when $\alpha<0.5$, it will produce a negative effect. At the same time, combined with the analysis of the above test data, this section specifically calculates the fiber confounding coefficient of the HFRC test block cube compression and splitting tensile and bending resistance. The results are shown in Table $4 ; f_{\mathrm{cc}}$ is the strength of the HFRC test block, and $F_{\mathrm{ct}}$ is the strength of the single fiber concrete test block corresponding to the same volume. It can be seen that the result of the fiber confounding effect coefficient is basically consistent with the comparison of the above test results. When $\alpha<0.5$, the mechanical properties of HFRC test block are slightly weaker than those of single fiber concrete with equal volume rate, indicating that the fiber mixing effect is negative under the combination of the two 
kinds of fibers at this time. When $\alpha>0.5$, the performance of the HFRC test block is better than that of single fiber concrete; at this time, the fiber mixing effect under the combination of dosage is positive.

\section{Conclusion}

(1) The incorporation of fibers can significantly improve the mechanical properties of the concrete matrix such as splitting tensile and bending toughness, but, at the same time, it also reduces the compressive strength of the concrete matrix to a certain extent. When single doped basalt fiber, single doped polyacrylonitrile fiber, and fiber are mixed, the splitting tensile performance of concrete is up to $5.5 \%, 12.9 \%$, and $18.6 \%$ higher than that of PC, respectively; the flexural peak value is up to $18.3 \%, 29.9 \%$, and $34.8 \%$ higher than that of PC. The maximum toughness ratio is $2.5,2.7$, and 4.4 , respectively; the compressive strength of the cube is increased by $-12.9 \%,-5.6 \%$, and $1.6 \%$, respectively, compared with $\mathrm{PC}$; the compressive strength of the axial center is increased by $-3.9 \%$, 2.8 , and $1.3 \%$ compared with that of PC.

(2) The incorporation of fiber has little effect on the compressive elastic modulus of the concrete matrix. In the case of single and mixed fiber, the influence of the fiber on the compressive elastic modulus of the concrete matrix is between $-4.1 \%$ and $1.3 \%$. At the same time, fiber can also enhance the mechanical properties of early-age concrete such as compression, tension, and bending.

(3) Through the analysis results of the test data and the calculation results of the fiber mixing effect coefficient, within the fiber volume content range specified in this article, a good mixing effect is shown between basalt fiber and polyacrylonitrile fiber. Based on all the experimental data and calculation results, the optimal blending amounts of basalt and polyacrylonitrile fiber obtained in this paper are $V_{B}=0.15 \%$ and $V_{P}=0.11 \%$.

\section{Data Availability}

The data used to support this study are available from the corresponding author upon request.

\section{Disclosure}

A preprint has previously been published (https://www. researchgate.net/publication/342765161) [27].

\section{Conflicts of Interest}

The authors declare that they have no conflicts of interest.

\section{Acknowledgments}

This research was funded by the National Natural Science Foundation of China through Grant nos. 51708047,
51778069, and 51978081; the Natural Science Foundation of Hunan Province through Grant no. 2019JJ50670; and the Excellent Youth Project of Hunan Provincial Department of Education through Grant no. 19B013.

\section{References}

[1] J. Li, Z. Wu, C. Shi, Q. Yuvan, and Z. Zhang, "Durability of ultra-high performance concrete-a review," Construction and Building Materials, vol. 255, Article ID 119296, 2020.

[2] Z. Zhang, X. Shao, and P. Zhu, "Direct tensile behaviors of steel-bar reinforced ultra-high performance fiber reinforced concrete: effects of steel fibers and steel rebars," Construction and Building Materials, vol. 243, Article ID 118054, 2020.

[3] Z. Wu, C. Shi, and K. H. Khayat, "Investigation of mechanical properties and shrinkage of ultra-high performance concrete: influence of steel fiber content and shape," Composites Part B: Engineering, vol. 174, Article ID 107021, 2019.

[4] G. B. Maranan, A. C. Manalo, B. Benmokrane, W. Karunasena, P. Mendis, and T. Q. Nguyen, "Flexural behavior of geopolymer-concrete beams longitudinally reinforced with GFRP and steel hybrid reinforcements," Engineering Structures, vol. 182, pp. 141-152, 2019.

[5] M. Singh, A. H. Sheikh, M. S. Mohamed Ali, P. Visintin, and M. C. Griffith, "Experimental and numerical study of the flexural behaviour of ultra-high performance fibre reinforced concrete beams," Construction and Building Materials, vol. 138, pp. 12-25, 2017.

[6] M. F. Al-Lebban, A. I. Khazaly, R. Shabbar, Q. A. Jabal, and L. A. R. Al Asadi, "Effect of polypropylene fibers on some mechanical properties of concrete and durability against freezing and thawing cycles," Key Engineering Materials, vol. 895, pp. 130-138, 2021.

[7] A. Abdelrahman, A. Wael, and F. Murad, "Structural performance and moment redistribution of basalt FRC continuous beams reinforced with basalt FRP bars," Engineering Structures, vol. 240, Article ID 112390, 2021.

[8] J. He, J. Shi, Y. Zhang et al., "Study on tensile stress-strain relationship of BFRC," IOP Conference Series: Earth and Environmental Science, vol. 643, no. 1, Article ID 012040, 2021.

[9] X.-F. Chen, C.-Q. Quan, and C.-J. Jiao, "Experimental study of chloride resistance of polypropylene fiber reinforced concrete with fly ash and modeling," Materials, vol. 14, no. 16, p. 4417, 2021.

[10] L. Yang, H. Xie, S. Fang, C. Huang, A. Yang, and Y. J. Chao, "Experimental study on mechanical properties and damage mechanism of basalt fiber reinforced concrete under uniaxial compression," Structures, vol. 31, pp. 330-340, 2021.

[11] Y. Aravind Sai and M. Anil Kumar, "Experimental study on mechanical properties of polypropylene fiber reinforced concrete with silica fume," IOP Conference Series: Materials Science and Engineering, vol. 1136, no. 1, Article ID 012020, 2021.

[12] K. Cui, L. Xu, X. Li et al., "Fatigue life analysis of polypropylene fiber reinforced concrete under axial constant-amplitude cyclic compression," Journal of Cleaner Production, vol. 319, Article ID 128610, 2021.

[13] S. Ashkan, N. Parisa, P. Ali Shadmani, M. M. Moein, H. Moez, and E. H. Vishki, "Prediction of mechanical properties of lightweight basalt fiber reinforced concrete containing silica fume and fly ash: experimental and numerical assessment," Journal of Building Engineering, vol. 32, Article ID 101732, 2020. 
[14] H. Ahmad, M. Sheikh, Neaz, and N. S. Hadi Muhammad, "Behavior of GFRP bar-reinforced hollow-core polypropylene fiber and glass fiber concrete columns under axial compression," Journal of Building Engineering, vol. 44, Article ID 103245, 2021.

[15] M. Khan, M. Cao, and M. Ali, "Cracking behaviour and constitutive modeling of hybrid fibre reinforced concrete," Journal of Building Engineering, vol. 30, Article ID 101275, 2020.

[16] C. H. E. N. Qian, L. Xu, and F. Wu, "Experimental investigation on strength of steel- polypropylene hybrid fiber reinforced ultra high performance concrete," Bulletin of the Chinese Ceramic Society, vol. 39, no. 3, pp. 740-748, 2020.

[17] H. Wu, Z. Pei, and X. Yang, "Experiment on crack resistance of steel-polypropylene hybrid fiber reinforced concrete," Journal of Huazhong University of Science and Technology (Nature Science Edition), vol. 48, no. 4, pp. 43-47, 2020.

[18] C. Yang, C. Huang, and Y. Che, "Mechanical properties and impermeability of hybrid fiber reinforced concrete," Journal of Building Materials, vol. 11, no. 1, pp. 89-93, 2008.

[19] H. Pan, "Experimental study on mechanical property of basalt fiber reinforced concrete," Bullention of the Chinese Ceramic Society, vol. 28, no. 5, pp. 955-959, 2009.

[20] J. He, J. Shi, Z. Wang et al., "Effect of hybrid effect on the mechanical properties of hybrid fiber reinforced concrete," Fiber Reinforced Plastics/Composites, vol. 9, pp. 26-32, 2016.

[21] Q. Fu, W. Xu, M. Bu, B. Guo, and D. Niu, "Effect and action mechanism of fibers on mechanical behavior of hybrid basaltpolypropylene fiber-reinforced concrete," Structures, vol. 34, no. 34, pp. 3596-3610, 2021.

[22] A. Krishna and S. R. M. Kaliyaperumal, "Effect of elevated temperature on strength and ductility of axially loaded hybrid fiber reinforced concrete columns," Structures, vol. 34, pp. 3548-3556, 2021.

[23] R. P. Borg, O. Baldacchino, and L. Ferrara, "Early age performance and mechanical characteristics of recycled PET fibre reinforced concrete," Construction and Building Materials, vol. 108, pp. 29-47, 2016.

[24] D. Shen, X. Liu, Q. Li, L. Sun, and W. Wang, "Early-age behavior and cracking resistance of high-strength concrete reinforced with Dramix 3D steel fiber," Construction and Building Materials, vol. 196, pp. 307-316, 2019.

[25] Z. Liu, W. Robert, F. Du et al., "A study on avalanches of early age basalt fiber reinforced concrete beams during flexure," Journal of Cleaner Production, vol. 279, Article ID 123695, 2021.

[26] H. Guo, L. Jiang, J. Tao, Y. Chen, Z. Zheng, and B. Jia, "Influence of a hybrid combination of steel and polypropylene fibers on concrete toughness," Construction and Building Materials, vol. 275, Article ID 122132, 2021.

[27] 2020 https://www.researchgate.net/publication/342765161_Study_ on_mechanical_properties_and_optimum_fiber_content_for_ basaltpolyacrylonitrile_hybrid_fiber_reinforced_concrete. 